\title{
Optimal PID controller design using artificial bee colony algorithm for robot arm
}

\author{
Ghassan A. Sultan, Muhammed K. Jarjes \\ Northern Technical University, Technical Engineering College, Department of Medical Instrumentation Technical \\ Engineering, Mosul, Iraq
}

\begin{tabular}{|c|c|}
\hline Article Info & ABSTRACT \\
\hline & \multirow{6}{*}{$\begin{array}{l}\text { Proportional integral derivation (PID) controller is used in this paper for } \\
\text { optimal design, and tuning by zeigler and nichol ( } \mathrm{ZN}) \text { with artificial bee } \\
\text { colony algorithm. The best parameter were found using these algorithms for } \\
\text { best performance of a robot arm. The advantage of using ABC were } \\
\text { highlighted. The controller using the new algorithm was tested for valid } \\
\text { control process. Different colony size has been performed for tuning process, } \\
\text { settling time, from time domain performance, rise time, overshot, and steady } \\
\text { state error with ABC tuning give better dynamic performance than controller } \\
\text { using the }(\mathrm{ZN}) \text {. }\end{array}$} \\
\hline Received May 18, 2020 & \\
\hline Revised Jul 22, 2020 & \\
\hline Accepted Aug 8, 2020 & \\
\hline Keywords: & \\
\hline & \\
\hline
\end{tabular}

optimization

PID controller

Robot arm

Ziegler-nichols method

This is an open access article under the CC BY-SA license.

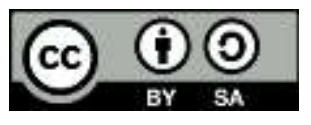

\author{
Corresponding Author: \\ Ghassan Ahmed Sultan \\ Department of Medical Instrumentation Technology Engineering \\ Northern Technical University \\ Mosul, Iraq \\ Email: ghassankassab@ntu.edu.iq
}

\section{INTRODUCTION}

Generally, the body of a robot has a range of joints. Ignoring the effect of joints movements, the servo mechanism is used in the designing process the control of the arm joints. The hydraulic or gas actuator for industrial robot are used instead of dc servomotor. Due to their high speed in position management characteristic, the DC motors are widely used in the field of trade. The mechanism is normally associate with the armature control motor. The robot arm should be connected to the motor via a gear system [1]. Using proportional integral derivative (PID) controller for controlling speed and location of the robot arm. The objective of this research is to design a system exploitation artificial bee colony optimization (ABC). To optimize the gains, ABC algorithm is employed leading to application of the value into the controller of the plant. The gains of the PID controller are optimized by the logarithm for a given plant. Thus the error is detected by the controller depending on the proportional gain, whereas elimination of steady state error and stop over shoot is facilitated by the integral derivative gain [2-4]. Using ABC formula algorithm to perform the calibration and the controller leading to evaluation of the optimum controller on each occasion [5, 6]. This indicates that the system performance optimum calibration can be reached using exploiting the $\mathrm{ABC}$ technique. The result of the ABC ultimate system with classical tuned system $[7,8]$. 


\section{MATHEMATICAL MODEL OF ROBOT}

Hardness and gravity has no effect on the arm of the robot as shown in Figure 1 [9]. Figure 2 shows the robot joint system $[10,11]$. The dynamic movement of the system in the arm is shown in the following equations $[12,13]$.

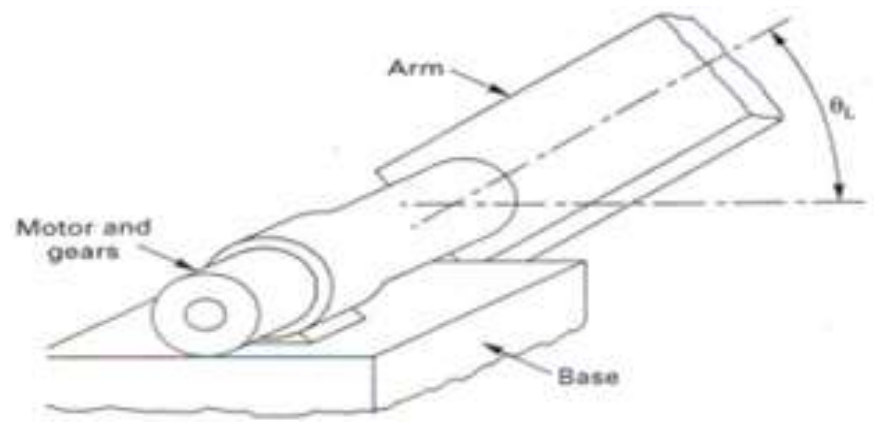

Figure 1. Typical one-joint robot arm

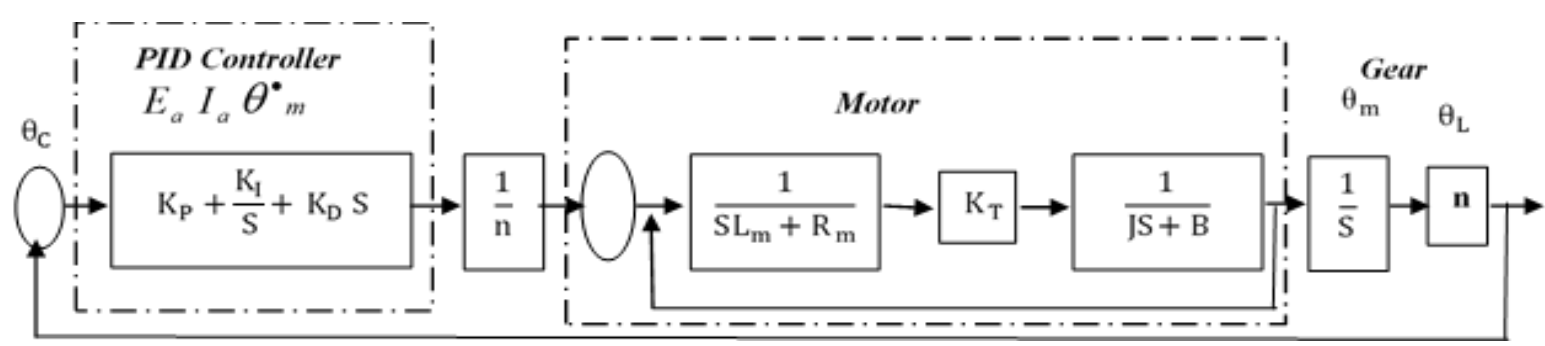

Figure 2. Control system in a robot joint

$$
\begin{aligned}
& \mathrm{e}_{\mathrm{a}}(\mathrm{t})=\mathrm{e}_{\mathrm{m}}(\mathrm{t})+R_{m} i_{a}(t)+L_{m} \frac{d i_{a}(t)}{d t} \\
& e_{m}(t)=K_{m} \frac{d \theta_{m}(t)}{d t} \\
& \mathrm{~T}_{m}=K_{T} I i_{a}(t) \\
& T_{m}=B \frac{d \theta_{m}(t)}{d t}+J \frac{d^{2} \theta_{m}(t)}{d t^{2}} \\
& T_{m}=n^{2} J l+J_{m} \\
& B=n^{2} B l+B_{m} \\
& \theta_{L}=n \theta_{m}
\end{aligned}
$$

The equations simplified and get the ratio of $\frac{\boldsymbol{\theta}_{L}(\mathrm{~S})}{\boldsymbol{E}_{\boldsymbol{a}}(\mathrm{S})}$ so the transfer function will be getting as follow:

$$
\frac{\theta_{L}(\mathrm{~S})}{E_{a}(\mathrm{~S})}=\frac{n K_{T}}{L_{m} J \mathrm{~S}^{3}+\left(J R_{m}+B L_{m}\right) \mathrm{S}^{2}+\left(K_{m} K_{T}+B R_{m}\right) \mathrm{S}}
$$

where.

$\mathrm{Rm}$ is the resistance of armature- winding $(\mathrm{Ohm}(\Omega))$

ia is the current of armature-winding (Ampere (A))

$\mathrm{Lm}$ is the armature-winding inductance $(\operatorname{Henry}(\mathrm{H}))$

em is the back emf voltage (Volt (V))

Tm is the motor torque (N.M) 
$\mathrm{Km}$ is the back emf constant (volt/( $\mathrm{rad} / \mathrm{sec}))$

$\mathrm{KT}$ is the constant of motor torque (N.m/A)

$\mathrm{J}$ is the motor and robot arm moment of inertia $(\mathrm{kg} / \mathrm{rad})$

$\theta \mathrm{m}$ is the motor shaft angular displacement (rad)

$\theta \mathrm{c}$ is the reference input angular displacement ( $\mathrm{rad})$

$\theta \mathrm{L}$ is the robot arm angular displacement (rad)

$B$ is the motor and robot arm viscous-friction coefficient $(\mathrm{N} . \mathrm{m} / \mathrm{rad} / \mathrm{sec})$

$\mathrm{N}$ is the ratio of the gear $(\mathrm{N} 1 / \mathrm{N} 2)$.

The following parameters represent the robot arm control system:-J=2 kg.m2/rad, KT=38 N.m/A, Lm=2 H, $\mathrm{Rm}=21 \Omega, \mathrm{B}=1 \mathrm{~N} \cdot \mathrm{m} / \mathrm{rad} / \mathrm{sec}, \mathrm{n}=1 / 20$, and $\mathrm{Km}=0.5 \mathrm{~V}(\mathrm{rad} / \mathrm{sec})$. Figure 3 illustrate the single servo control system of the robot. [13].

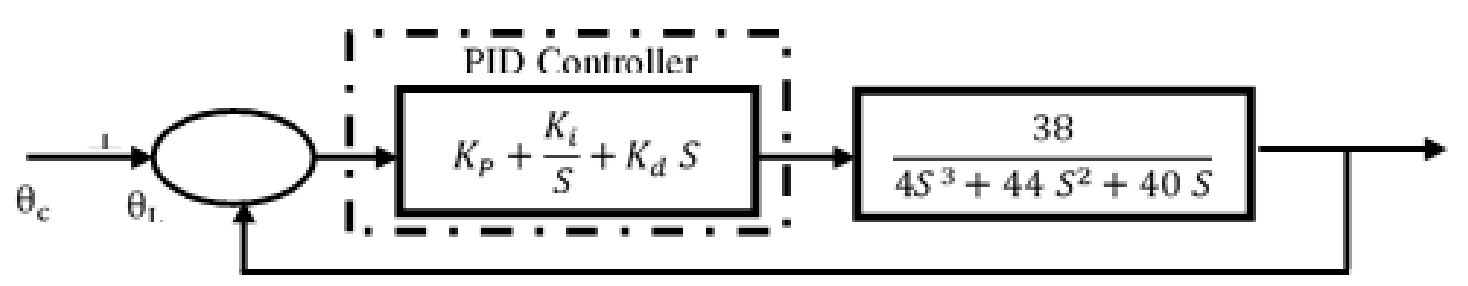

Figure 3. Robot jointed arm system

\section{TUNING PID CONTROLLER BASED ON ZIEGLER -NICHOLS RULE}

It is necessary to use a good tuning of the controlling parameters in order to get better performance and control with the correct parameters. In the case of using inaccurate values of the controller parameters, the performance of the system will be adequate in characteristics and also become unstable [14]. To get the closed-loop transfer function, it is done by choosing the controller setting values for KP, KI and KD, and this is achieved by setting the $\mathrm{KI}=0$ and $\mathrm{KD}=0$. System stability is marginal or acceptable occur when the value of KP is chosen so that sustainable fluctuation occurs using the Routh stability standard. This sustainable fluctuation can be obtained at the value of $\mathrm{KP}=11.57$, according to the study of the coefficients of the first column of the Routh table, and therefore the decisive gain, $\mathrm{Kcr}=11.57$. Based on the value of $\mathrm{w}=3.16 \mathrm{rad} / \mathrm{sec}$. thus, the continuous oscillation period (Pcr) is $2 \pi / \mathrm{w}=2$ seconds. To discover the number of times the fluctuation (w), S is replaced by jw in the properties equation. Return to Table 1, the parameters KP, KI and $\mathrm{KD}$ will be as follows [15, 16], KI=1.2 Kcr/Pcr=6.94, KP=0.6, K_D=0.075 K_cr×P_cr=1.73, and Kcr=6.94

Table 1. Tuning rule by ziegler-nichols

\begin{tabular}{cccc}
\hline Type of controller & $\mathrm{K}_{\mathrm{D}}$ & $\mathrm{K}_{\mathrm{P}}$ & $\mathrm{K}_{\mathrm{I}}$ \\
\hline PID & $0.075 \mathrm{Kcr} * \mathrm{Pcr}$ & $0.6 \mathrm{Kcr}$ & $1.2 \mathrm{Kcr} / \mathrm{Pcr}$ \\
PI & 0 & $0.45 \mathrm{Kcr}$ & $0.54 \mathrm{Kcr} / \mathrm{Pcr}$ \\
$\mathrm{P}$ & 0 & $0.5 \mathrm{Kcr}$ & 0 \\
\hline
\end{tabular}

MATLAB program can be easily to obtain the close-loop unit step system response by using the PID controller. Simulating result shows that the maximum over shoot is quit high (approximate 63\%). However, the controller parameter can be tuned by software to reduce this value. It should be easily approached that a fine tuning starting point can be acquired through ziegler-nichols tuning rule where it's value is approximate halve that obtained [17]. $\mathrm{KP}=15.26, \mathrm{KI}=6.94$ and $\mathrm{KD}=8.39$. The PID control unit equation of transfer function is:

$$
G_{C}(S)=\frac{K_{D} S^{2}+K_{P} S+K_{I}}{S}
$$

Table 2 contains the gain values of the PID controller.

$$
\mathrm{G}_{\mathrm{C}}(\mathrm{S})=\frac{8.39 \mathrm{~S}^{2}+15.26 \mathrm{~S}+6.94}{\mathrm{~S}}
$$


Table 2. PID controller gain magnitudes

\begin{tabular}{cccc}
\hline & KD & KI & KP \\
\hline Gain magnitudes & 8.39 & 6.94 & 15.26 \\
\hline
\end{tabular}

According to the algorithm acquired above, Figure 4 shows the step response with a conventionally tuned PID controller.

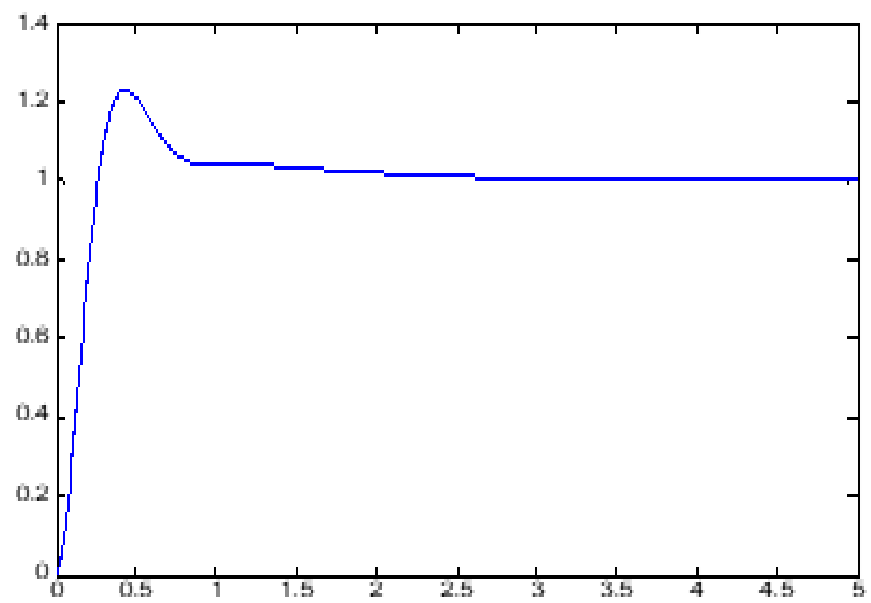

Figure 4. Step response system with PID controller unit

Depending on what was obtained from the results above. The following values can be obtained for the parameters of rising time, maximum overshooting and settling time which is $0.2 \mathrm{sec}, 23.9 \%$ and $2 \mathrm{sec}$. respectively. Among the above values, we conclude that the system has not been better tuned. Therefore, to obtain the best possible results, use the artificial bee colony optimization (ABC) technique. The technical requirements for this system are shown in Table 3 [15].

Table 3. System requirements

\begin{tabular}{cccc}
\hline & Settling Time (Sec) & Max Over Shoot & Rise Time (Sec) \\
\hline specification of the system & $<0.9$ & $<5 \%$ & $<0.5$ \\
\hline
\end{tabular}

\section{ARTIFICIAL BEE COLONY ALGORITHM (ABC)}

The artificial bee colony contains the following groups. The first group is the worker bees, second one is the watcher bees, and finally is the searcher bee. Also the colony is divided into two parts, the first colony section contains the worker artificial bees and the other section is the watcher bees. In this colony, jobs are distributed among the bees for the purpose of being carried out by specialized personal [18, 19]. These bee specialists try to greatly increase the amount of nectar stored in the hive to the optimum, and this is achieved by a good distribution of worker and self-regulation [20, 21]. The worker bees that abandoned the source of food becomes a searcher. For the source of food, each one bee is specified to the source of food, that is, the number of bees working have an equal amount of energy sources surrounding the hive. The food source position means a probable process optimization solution and the nectar origin of a food source depend on the goodness (fitness) linked with the solution [16, 17]

\subsection{The algorithm of $\mathrm{ABC}$}

The main steps (semi-coding) to initialize the artificial BA are:

a) Initialize the solutions of a population:

$$
v_{i j}=x_{i j}+\phi_{i j}\left(x_{i j}-x_{k j}\right)
$$


where, $x i j, i=1$. FSN, (FSN is the food source number) $\mathrm{j}$ equal one, and D is the controller dimension problem (called $\mathrm{K}_{\mathrm{P}}, \mathrm{K}_{\mathrm{I}}$ and $\mathrm{K}_{\mathrm{D}}$ ), where $\mathrm{D}$ equal three, ${ }^{\phi}$ is also a random number in the domain[-1,1] and $\mathrm{k}=1$. SN.

b) Evaluate the population (colony size).

c) Cycle equals one

d) Repeat

e) By using repeat (4), it may give to a new solutions xij for the employed bees and assess the solution.

f) Application for processing of a greedy choice.

g) Compute the probability values $\mathrm{Pi}, \mathrm{j}$ for the solutions $\mathrm{xi}, \mathrm{j}$ by the item ( 3 and 4 ).

$$
p i=\frac{\text { fit }_{i}}{\sum_{n=1}^{s n} f i t_{n}}----(10)
$$

h) Create new solutions xi, $\mathrm{j}$ for the on looking from the selected solutions $\mathrm{xi}, \mathrm{j}$ relying on Pi, $\mathrm{j}$ and assess the solutions.

i) Application for the processing of greedy choice.

j) If the scout exist, determine abandoned solution for it, and exchange it with a novel irregular produced solution xi,j by select the item (4 and 5).

$$
x_{i}^{j}=x_{\min }^{j}+\phi\left(x_{\max }^{j}-x_{\min }^{j}\right)
$$

where, is also a random number in the domain $[0,1]$.

k) Save the best achieved solution till now.

1) Cycle becomes cycle+1.

m) Till cycle becomes MCN (maximum cycle number).

\subsection{Objective function}

The new Fitness function for the parameters optimization of PID controller is known as:

$$
\mathrm{F}=\mathrm{Wmax} .(1-\exp (-0.5)) \cdot(\mathrm{Mp}+\mathrm{Ess})+\mathrm{Wmin} \cdot \exp (-0.5) \cdot(\mathrm{ts}-\mathrm{tr})
$$

where

$\mathrm{Mp}$ : is the greatest overshoot

Ess: steady state error

tr: rise time

$\mathrm{tS}$ : settling time

Wmax: max. inertia weight

Wmin: min. inertia weight

The Parameters of ABC algorithms for optimizing the PID controller is shown in Table 4.

Table 4. Parameters of ABC algorithms

\begin{tabular}{cc}
\hline Parameter & Values \\
\hline Colony size & 40 \\
No. of Iterations & 100 \\
Maximum Speed & 10 \\
(Wmax)Max. Inertia Weight & 0.9 \\
(Wmin)Min. Inertia Weight & 0.3 \\
\hline
\end{tabular}

\section{ABC-PID CONTROLLER}

In this work of research the ideal parameters (KP, KI and KD) were determined by the application of algorithm $(\mathrm{ABC})$ resulting in an impressive response rate. The $\mathrm{ABC}$ algorithms have been used to find the console parameters (PID) [21, 22]. The group of KP, KI and KD parameters can be used to achieve good system response and reduce performance parameters in the time domain, and minimize required including stability time (Ts), elevation time ( $\mathrm{Tr}$ ), maximum overflow (\% OS), and stable state error (ess). Figure 5 illustrates the robot arm design using the ABC-PID system [23-25]. 


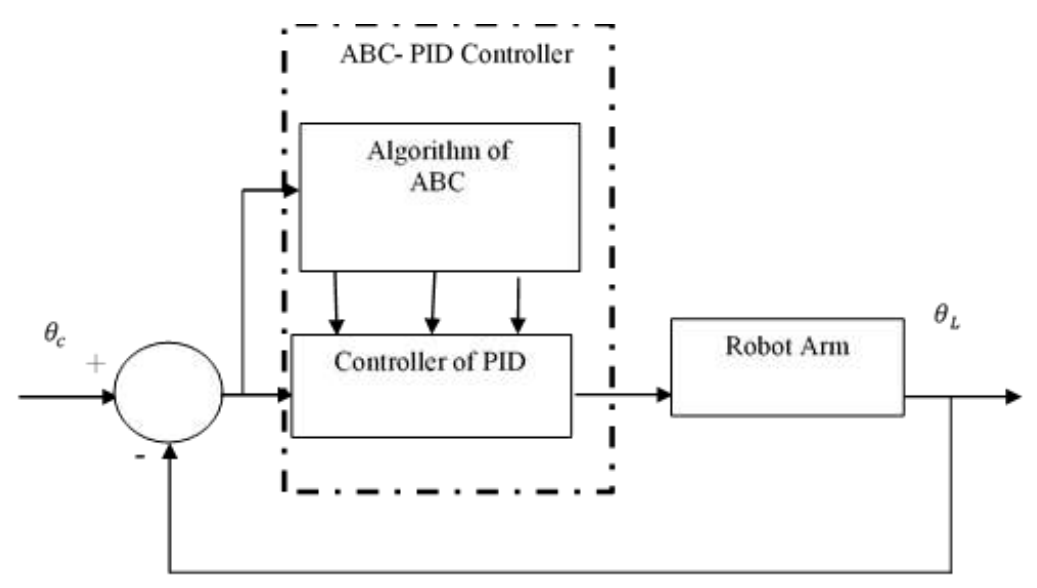

Figure 5. ABC-PID controller design for robot arm

\section{RESULTS AND SIMULATION}

Figures 6 and 7 illustrate the robot response to step unit by ABC-PID controller with colony size 20 and 40 respectively. Figures 8 and 9 with colony size 20 and 40 respectively illustrate the idea of how the $\mathrm{ABC}$ algorithm is spread to its final magnitude, and for $\mathrm{KP}, \mathrm{KI}$ and $\mathrm{KD}$ each gain is called particle. The parameters of the two controllers ZN-PID and ABC-PID are shown in Table 5.

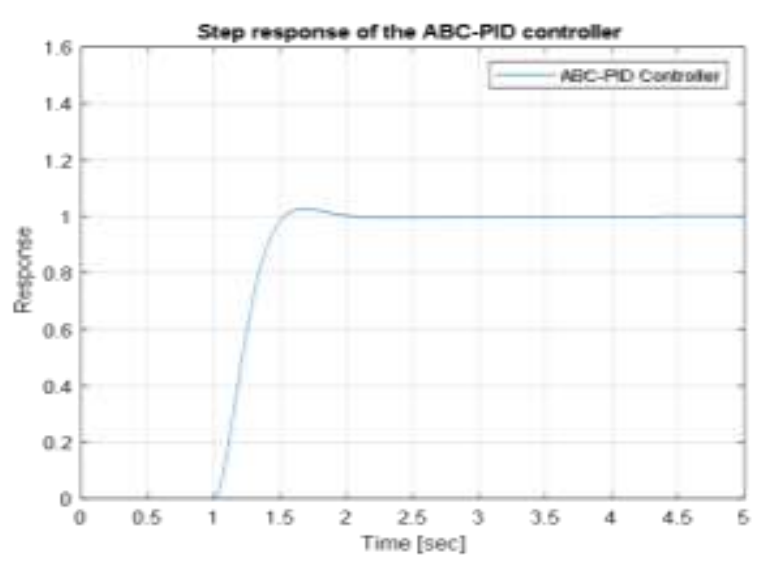

Figure 6. Robot arm step response of ABC-PID controller with colony size 20

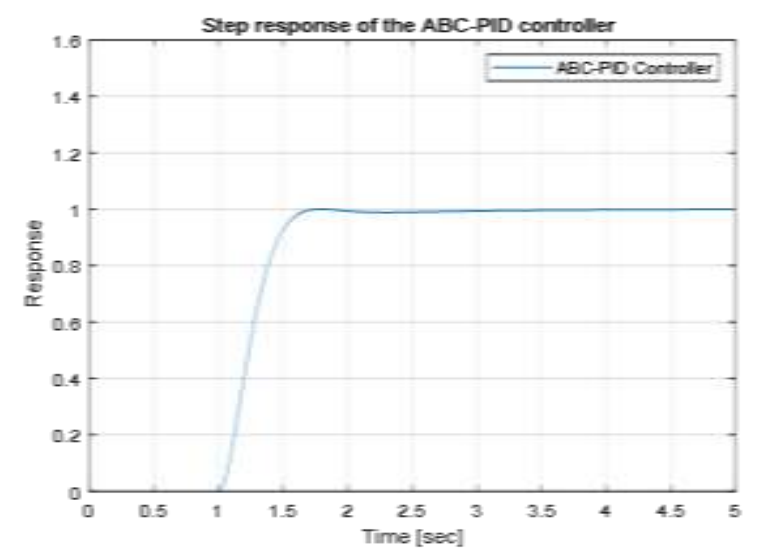

Figure 7. Robot arm step response of ABC-PID controller with colony size 40
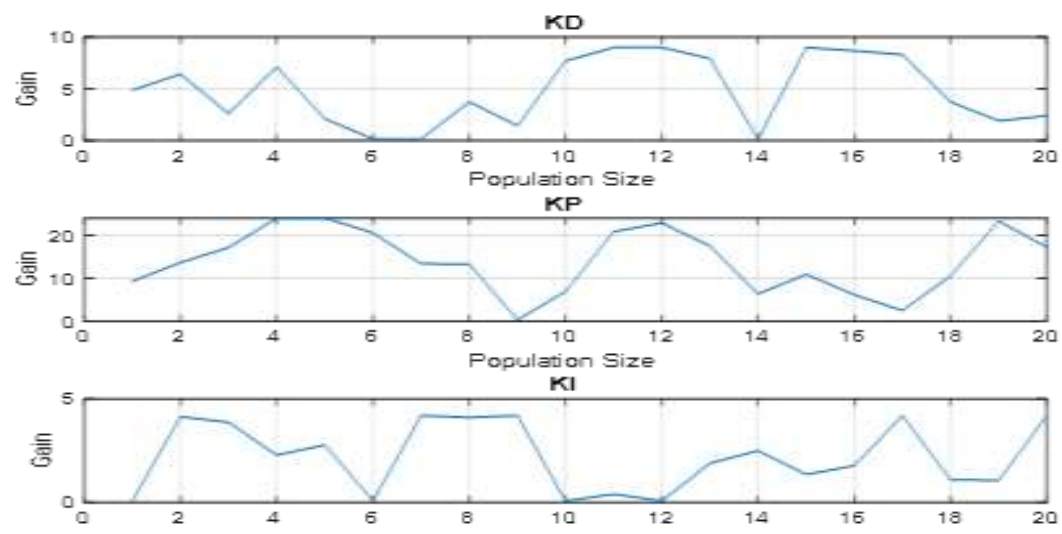

Figure 8. ABC-PID controller parameter with colony size 20 


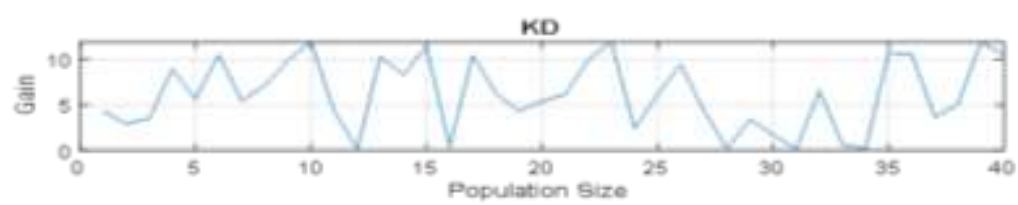

KP

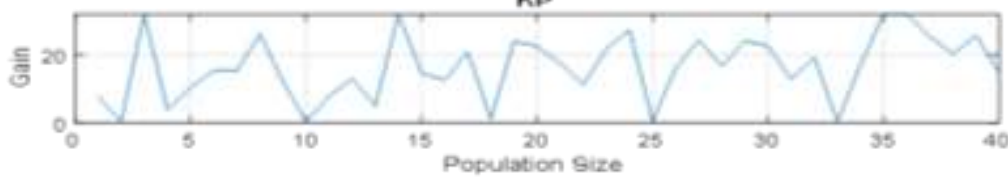

KI

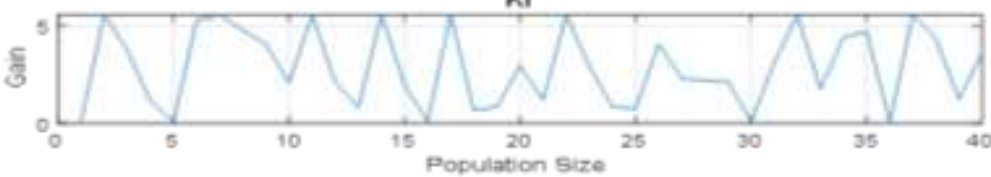

Figure 9. ABC-PID controller parameter with colony size 40

Table 5. Parameters for ZN-PID and ABC-PID controllers

\begin{tabular}{cccc}
\hline Controllers Parameters & ZN-PID & ABC-PID with colony size 40 & ABC-PID with colony size 20 \\
\hline Tr $(\mathrm{sec})$ & 0.2 & 0.387 & 0.332 \\
Ts $(\mathrm{sec})$ & 2 & 0.607 & 0.793 \\
Mp $\%$ & 23.9 & 0.0563 & 2.63 \\
$\mathrm{~K}_{\mathrm{D}}$ & 15.26 & 3.8375 & 4.6682 \\
$\mathrm{~K}_{\mathrm{I}}$ & 6.94 & 0.0160 & 0.001 \\
$\mathrm{~K}_{\mathrm{D}}$ & 8.39 & 4.3535 & 4.8809 \\
\hline
\end{tabular}

\section{CONCLUSION}

From above we can consider that the step of the responses obtained from the PID controller which was set in $\mathrm{ABC}$ method and within the colony size measurement 40 and 20 is better than the results compared with ziegler-nichols (and with the same colony size 40 and 20). The Ziegler-Nichols method is a good and effective way to allow the designer to evaluate the initial settings of the results from PID controller. The values of the step response results taken from the PID by designing the ABC method are better in terms of a maximum overshoot and settling time. According to the criteria for time domain performance such as settling time, rise time, overshoot, and steady-state error, the PID controller set by ABC is the better method that gives better dynamic performance compared to the way controllers set by ZN.

\section{REFERENCES}

[1] K Ogata, "Modern Control Systems," University of Minnesota, Prentice Hall, 2003.

[2] M. S. Alam, M. M. Islam, "Artificial Bee Colony algorithm with Self-Adaptive Mutation: A novel approach for numeric optimization," IEEE Region 10 Conference In TENCON, pp. 49-53, 2011.

[3] Karaboga, D., Basturk, B., "On the Performance of Artificial Bee Colony (ABC) Algorithm. Applied Soft Computing," vol. 8, no. 1, 687-697, 2008.

[4] Karaboga, D., Akay, B., "A Comparative Study of Artificial Bee Colony Algorithm," Applied Mathematics and Computation 214, pp. 108-132, 2009.

[5] Karaboga, D., Gorkemli, B., Ozturk, C., Karaboga, N., “A Comprehensive Survey: Artificial Bee Colony (ABC) Algorithm and Applications," Artificial Intelligence Review, Online First TM 2012, vol. 42, pp. 21-57, 2014.

[6] S. Pareek, M. Kishnani, R. Gupta, "Application of Artificial Bee Colony Optimization For Optimal PID Tuning," IEEE International Conference on Advances in Engineering \& Technology Research, 2014.

[7] L. D. Berkovitz, "Optimal control theory," Springer Science \& Business Media, 2013.

[8] N. Dey and T. Santra, "Application of PSO for optimizing gain parameters of a controller in real system,” 2015.

[9] L.phillips and D. Harbar, "Feedback Controller System," 3rd edition, Prentice Hall, 1996.

[10] R. A. Krohling and J. P. Rey, "Design of optimal disturbance rejection PID controllers using genetic algorithm," IEEE Trans. Evol. Comput., vol. 5, pp. 78-82, Feb. 2001.

[11] D. Karaboga, B.B., "A Powerful and Efficient Algorithm for Numerical Function Optinization: Artificial Bee Colony ABC Algorithm,” Journal Global Optimization, vol. 39, no. 3, pp. 459-471, 2007.

[12] Ramzy S. Ali, PhD, Ammar A. Aldair, PhD, "Design an Optimal PID Controller using Artificial Bee Colony and Genetic Algorithm for Autonomous Mobile Robot," International Journal of Computer Applications (0975-8887) vol. 100, no. 16, August 2014. 
[13] Chun Htoo Aung, Khin Thandar Lwin, and Yin Mon Myint, "Modeling Motion Control System for Motorized Robot Arm using MATLAB," World Academy of Science, Engineering and Technology 42, pp. 372-375, 2008.

[14] P. V. Savsani and R. L. Jhala, "Optimal Motion Planning For a Robot Arm by Using Artificial Bee Colony (ABC) Algorithm,” International Journal of Modern Engineering Research (IJMER), vol. 2, no. 6, pp. 4434-4438, 2012.

[15] G. Zhu and S. Kwong, "Gbest-Guided Artificial Bee Colony Algorithm for Numerical Function Optimization," Applied Mathematics and Computation, vol. 217, no. 7, pp. 3166-3173, Dec. 2010.

[16] A. A. Kesarkar, N. Selvaganesan, "Tuning of optimal fractional-order pid controller using an artificial bee colony algorithm," Journal of Systems Science \& Control Engineering, vol. 3, no. 1, pp. 99-105, 2015.

[17] W. Liao, Y. Hu, H. Wang, "Optimization of PID control for DC motor based on artificial bee colony algorithm," IEEE International Conference on Advanced Mechatronic Systems, pp. 23-27, 2014.

[18] Xiaojun Bi and Yanjiao Wang, "An improved artificial bee colony algorithm," 2011 3rd International Conference on Computer Research and Development, Shanghai, pp. 174-177, 2011. doi: 10.1109/ICCRD.2011.5764108.

[19] Y. F. Liu and S. Y. Liu, "A hybrid discrete artificial bee colony algorithm for permutation flowshop scheduling problem,” Applied Soft Computing Journal, vol. 13, no. 3, pp. 1459-1463, 2013.

[20] N. Elkhateeb and R. Badr, "A Novel Variable Population Size Artificial Bee Colony Algorithm with Convergence Analysis for Optimal Parameter Tuning," International Journal of Computational Intelligence and Applications, vol. 16, no. 3, pp. 1750018, Sep. 2017.

[21] Nasr A. Elkhateeb, (Ph.D., Modern University for Technology and Information), Ragia I. Badr (Professor, Cairo University), "Novel PID Tracking Controller for 2DOF Robotic Manipulator System Based on Artificial Bee Colony Algorithm," Electrical, Control and Communication Engineering, vol. 13, no. 1, pp. 55-62, 2017.

[22] Wang, L., Zhou, G., Xu, Y., Wang, S., Liu, M., "An effective artificial bee colony algorithm for the flexible jobshop scheduling problem,” Int. J. Adv. Manuf. Technol. vol. 60, pp. 303-315, 2012.

[23] Ian Griffin, “On-line PID Controller Tuning using Genetic Algorithms,” Dublin City University, 2003.

[24] J. P. P., J. P. Perez, R. Soto, A. Flores, F. Rodriguez, and J. L. Meza, "Trajectory Tracking Error Using PID Control Law for Two-Link Robot Manipulator via Adaptive Neural Networks," Procedia Technology, vol.3, pp. 139-146, 2012.

[25] S. S. Dahiya, J. K. Chhabra and S. Kumar, "Application of Artificial Bee Colony Algorithm to Software Testing,"2010 21st Australian Software Engineering Conference, Auckland, pp. 149-154, 2010. doi: 10.1109/ASWEC.2010.30.

\section{BIOGRAPHIES OF AUTHORS}

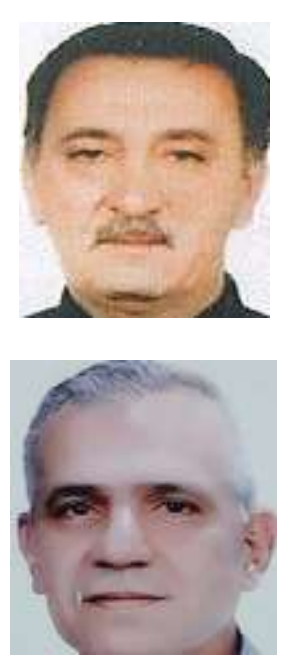

Ghasaan A. Sultan. He was born in Mosul in Iraq in 1962. He has got his BBc in electrical engineering in Raylovac academia in Sarajevo in Yugoslavia in 1985. He has got his MSc Electronics system in School of Electrical Engineering in University of Belgrade in 1987. He published two papers. Currently he is a lecturer in the department of medical instrumentations in the Engineering technical college of Mosul in Northern Technical University-Iraq.

Muhammed K. Jarjes. He was born in Mosul in Iraq in 1965. He has got his BBc in Electronics system engineering from cranfield university in England in 1989. He has got his MSc electronics from university of Mosul in 1995. He published two papers. Currently he is a lecturer in the department of medical instrumentations in the Engineering technical college of Mosul in Northern Technical University-Iraq. 